\title{
Regulatory Assessment Identifier
}

National Cancer Institute

\section{Source}

National Cancer Institute. Regulatory Assessment Identifier. NCI Thesaurus. Code C94052.

A unique symbol that establishes identity of the regulatory assessment. 